\title{
Effect of an antepartum Pap smear on the coverage of a cervical cancer screening programme: a population-based prospective study Mari Nygård ${ }^{*}$, Anne-Kjersti Daltveit ${ }^{2,3}$, Steinar $\varnothing$ Thoresen $^{1}$ and Jan F Nygård ${ }^{1}$
}

Address: ${ }^{1}$ Department of Screening-based Research, The Cancer Registry of Norway, Oslo, Norway, ${ }^{2}$ Department of Public Health and Primary Health Care, Section for Epidemiology and Medical Statistics, University of Bergen, Bergen, Norway and ${ }^{3}$ Medical Birth Registry of Norway, Norwegian Institute of Public Health, Bergen, Norway

Email: Mari Nygård* - mari.nygard@kreftregisteret.no; Anne-Kjersti Daltveit - Anne.Daltveit@isf.uib.no; Steinar Ø Thoresen - sth@kreftregisteret.no; Jan F Nygård - j.f.nygard@kreftregisteret.no

* Corresponding author

Published: 23 January 2007

BMC Health Services Research 2007, 7:10 doi:10.1 186/1472-6963-7-10
Received: 08 August 2006

Accepted: 23 January 2007

This article is available from: http://www.biomedcentral.com/1472-6963/7//0

(c) 2007 Nygård et al; licensee BioMed Central Ltd.

This is an Open Access article distributed under the terms of the Creative Commons Attribution License (http://creativecommons.org/licenses/by/2.0), which permits unrestricted use, distribution, and reproduction in any medium, provided the original work is properly cited.

\begin{abstract}
Background: Almost one-third of Norwegian women aged 25-69 years invited to have a Pap smear do not attend during the recommended period, and thus constitute a population with highrisk of cervical cancer (CC). Since the incidence of precancerous lesions of the cervix peak with occurrence of pregnancies within the same decade in women aged 25 to 35 years of age, antepartum care presents an opportunity to offer a Pap smear thereby increasing the coverage of the programme. The study objective was to describe the effect of the antepartum Pap smear on the coverage of a cytological CC screening programme.
\end{abstract}

Methods: Among 2175762 women resident in Norway in 31.12.1996, all women who gave birth in 1996-7 were identified from the Medical Birth Registry of Norway. Attendance to the cervical cancer screening was assessed by linkage to the Cytology Registry separately for the pregnant and non-pregnant women cohorts. The results were stratified by age, history of previous Pap smear and history of invitation to the $\mathrm{CC}$ screening programme. Logistic regression was used to estimate the relative probabilities of having a Pap smear adjusted for age, screening history, and time since invitation, for pregnant and non-pregnant women, respectively.

Results: $69 \%$ of the pregnant women had a Pap smear during one year of follow-up since beginning of the pregnancy with the majority taken during the antepartum period. Irrespectively of age or history of having a Pap smear, pregnant women were 4.3 times more likely to have a Pap smear during follow-up compared to non-pregnant women. $63.2 \%$ of the pregnant women had a smear as response to the invitation letter compared to $28.7 \%$ of the non-pregnant women, OR $=2.1$ ( $95 \%$ $\mathrm{Cl}$ I.9 to 2.4). As an indication of "over-screening", 5397 pregnant women (57.8\%) with a smear shortly before the start of follow-up also had a new Papsmear, compared to 83023 (32.3\%) in nonpregnant.

Conclusion: Pap smear screening during pregnancy increases the coverage of the CC screening programme. The contribution of the antepartum Pap smear to "over-screening" exists but its effect is modest in countries where women on average become pregnant after the start of recommended age of screening. 


\section{Background}

Early detection of cervical cancer (CC) has reduced the mortality and morbidity of cervical cancer worldwide [1], and it has been reported that both organised and opportunistic Pap smear taking has lowered incidence rates of CC [2]. However, the importance of obtaining and maintaining a high coverage within the target population has been unanimously recognised [3-8] and several studies support the observation that the decrease in incidence rates is more evident in countries with organised screening programmes [5,9-11].

The Norwegian co-ordinated CC screening programme was introduced in 1995 and $71 \%$ of the women 25-69 years of age in Norway had a Pap smear in 1998 to 2000 [12]. More than $50 \%$ of the CC cases diagnosed however among the remaining group of non-participants, constituting a population at high-risk of cervical cancer [13].

To minimize the costs of early detection of CC for society, only women without a normal Pap smear in a three years period are identified from the registry files and are invited to be screened [12]. Not all women attend following the invitation; in a Swedish study it was reported that nonattendance to cervical screening was positively associated with time-consuming and economical barriers [14].

The peak age of incidence of pre-cancerous lesions of the cervix peaks with the occurrence of pregnancies in the age range 25-35 $[15,16]$. From this perspective, antepartum care presents an opportunity to offer a Pap smear to women who otherwise might not go for routine health check-ups, and a means to increase coverage of the programme. Screening of this population can however cause "over-screening" given many of these women might have had a Pap shortly before the start of the pregnancy. Understanding the potential differences in the actual pattern of Pap smear taking activity among pregnant and non-pregnant women would help public health policy makers to recognise conflicting attitudes towards screening and to evaluate the effect of antepartum Pap smear as a routine activity.

The objective of this study is to describe the pattern of Pap smear taking activity and to estimate the impact of Pap smear screening in pregnant women on the overall coverage of the cervical cancer screening programme.

\section{Methods}

\section{Subjects}

All women resident in Norway in 31.12.1996 were identified from the Population Register. Women born before 1900 , diagnosed with invasive cervical cancer or underwent hysterectomy before 1996, died in 1997, or had inadequate data for estimating the pregnancy duration were excluded $(\mathrm{N}=39707)$. The final study population consisted of 2175762 females and the personal identification number (PIN), a unique 11 digit code, identified the subjects.

\section{The Norwegian co-ordinated CC screening programme}

A thorough description of the CC Screening programme is provided elsewhere [12]. Briefly, the Screening programme in Norway is built around the Cytology Register, which was established in 1992 to administrate the CC screening programme in Norway. It is mandatory to register PIN, date and result of every single Pap smear diagnosed in the country, irrespective of age of the woman, the nature of the health service (private/public) or the indication of the Pap smear. The PIN is used as a key for linkage between the Population and the Cytology Registry in order to identify all 25-69 year old women without a normal Pap smear during a period of three years, which is the recommended screening interval in Norway. From 1995 every women without a Pap smear in the period was identified on a monthly basis and they received personal invitations to participate. In this way, the opportunistic screening was integrated into the organised programme. To date information on more than six million Pap smears is available from the register.

\section{The Medical Birth Registry of Norway}

Established in 1967, the Medical Birth Registry of Norway (MBRN) was organised to conduct epidemiological surveillance of birth defects and other perinatal health problems in Norway aiming at prevention, as well as health services related to pregnancy, childbirth and the neonatal period, aiming at quality assurance. MBRN routinely registers the PIN and demographic information on the mother and the father, mother's health before and during pregnancy, including chronic diseases, complications during pregnancy and delivery as well as information on the infant, including birth defects and other perinatal problems.

Linkage between study population, MBRN and the Cytology Register The PIN was used to gather information about pregnancies from the MBRN and previous Pap smears from the population-based Cytology Register for each subject.

From the MBRN records all 116810 women who gave birth (or had abortion after the 16th gestation week) in 1996-7 in Norway ( $\mathrm{N}=121400$ ) were identified with information about exact date of birth, duration of the pregnancy, details about pregnancy outcome, multiple offspring, birth weight, and information on previous pregnancies. When there was more than one pregnancy registered per women for the period 1996-7 (2615 women had two and four women had three consecutive records during two years period) the first was included. 
When there was more than one offspring per birth (1904 twins, 58 triples and 2 women had 4 offspring) we used information about the first born. For 105 818, women the date of the last menstruation was available and used as the beginning of the antepartum period. For 10992 women (9.4\%) this information was missing and beginning of the pregnancy period was estimated by subtracting from date of birth 41 weeks if birth weight was $>3400$ gram, 40 weeks if 3200-3400 gram, 39 weeks if 2800-3000 gram, 38 weeks if $2600-2800$ gram, 37 weeks if 2400-2600 gram, 36 weeks if 2200-2400 gram, 35 weeks if 20002200 gram, 34 weeks if 1800-2000 gram, 33 weeks if $1600-1800$ gram, 32 weeks if $1400-1600$ gram, 31 weeks if 1200-1400 gram, 30 weeks if 1000-1200 gram, 29 weeks if $800-1000$ gram, 28 weeks if $600-800$ gram, 27 weeks if 400-600 gram.

For each study subject we identified the date and the diagnoses of the Pap smears from the Cytology Register. Subjects who received an invitation letter from the Cancer Registry of Norway were identified, together with the posting date of the invitation letter.

\section{Study cohorts}

We categorised the following three mutually exclusive cohorts, within the study population:

1. Pregnant women cohort $\left(C_{\text {preg }}\right)$ : subjects giving birth during the period \pm 3 month from the date 31.12.1996. $T_{0}$ is the date denoting the start of the follow-up. For subjects within the pregnant women cohort, $\mathrm{T}_{0}$ was the date when the antepartum period started, estimated individually for each subject as described above.

2. Reference cohort $\left(C_{r e f}\right)$ : subjects who neither gave birth nor were pregnant during this calendar period respective to the follow-up period of the pregnant women e.g. from 01.01.1996 to 31.12.1997. For the Reference cohort, $\mathrm{T}_{0}$, the date marking the start of the follow-up was randomly chosen for each subject from the same calendar period as for the $\mathrm{C}_{\text {preg. }}$.

3. Mixed cohort: all other subjects in the study population who gave birth in 1996-7 but were not included in the $\mathrm{C}_{\text {preg. }}$.

Pregnant women and reference cohort were followed up for one year (since $\mathrm{T}_{0}$ ) in the Cytology Register for Pap smears. To identify the pattern of attendance to screening for each subject, time since last Pap smear before $T_{0}$ was identified and stratified as the last Pap smear taken 1, 2, 3 or $>3$ years earlier. To evaluate the response to the invitation letter, we identified subjects who received an invitation to screening and stratified analyses by the assessed time since the invitation was mailed in relation to $\mathrm{T}_{0}$, i.e.
24 to 2 months prior to $\mathrm{T}_{0}$, one month prior to 3 months after the $\mathrm{T}_{0}$, more than three months after the $\mathrm{T}_{0}$.

\section{Statistical analyses}

The Kaplan-Meier method was used to estimate the cumulative probability of having a Pap smear since $\mathrm{T}_{0}$. [17]

We used unconditional logistic regression to compare the odds of having a Pap smear within 12 month after inclusion in the study for $C_{r e f}$ and $C_{\text {preg }}$. Odds ratios (OR) with $95 \%$ confidence intervals $(95 \% \mathrm{CI})$ were estimated both crude and adjusted for age, screening history and time since invitation.

\section{Results}

Altogether, 24297 women were assigned to the $C_{\text {preg' }} 2$ 060118 to the $C_{r e f}$ and 91347 to the mixed cohort. For the three cohorts, age distribution, history of the Pap smear and history of the invitation are given in Table $1.44 \%$ of the $C_{r e f}$ had Pap smears during the three years before $\mathrm{T}_{0}$ compared to $78 \%$ among the $C_{\text {preg }}$ reflecting the wider age span in the $C_{\text {ref }}$ (all female population) compared to $C_{\text {preg }}$ or mixed cohort (women of reproductive age). When only women 15 to 49 years of age were analysed, the proportion having had smears in the $C_{r e f}$ was $65 \%$ (data not shown). The occurrence of a Pap smear within one year after $\mathrm{T}_{0}$ was assessed separately for the $C_{\text {ref }}$ and $C_{\text {preg }}$ (Table 2 ). Overall, the proportion of women with Pap smears in the $C_{\text {preg }}$ was three times higher $(68.7 \%)$ than the $C_{r e f}$ $(20.8 \%)$.

Only women 15 to 44 years of age were included in the stratified analyses by Pap smear history, invitations and Kaplan-Meier analyses for estimating cumulative probability for having a Pap smear since $\mathrm{T}_{0}$. (Figure 1 ). By the end of the follow-up of one year, $31.6 \%$ of the $C_{\text {ref }}$ had a smear compared to $67.8 \%$ of the $C_{\text {preg. }}$. The linear increase of the cumulative probability of the Pap smear is an expected pattern for the screened population in Norway indicating the appropriate selection of the $C_{r e f}$ for current study.

\section{Compliance with the recommended screening interval of three years}

$80 \%$ of the $C_{\text {preg }}$ and $46 \%$ of the $C_{r e f}$ women with a Pap smear 2-3 years prior to $\mathrm{T}_{0}$ and next Pap smear within one year were classified as those who were following the recommendations. $76.2 \%$ of the $C_{\text {preg }}$ and $23.1 \%$ of the $C_{\text {ref }}$ women women with a smear more seldom than recommended screening interval had a Pap smear within one year. $57.8 \%$ of $C_{\text {preg }}$ and $32.3 \%$ of the $C_{\text {ref }}$ women with a smear taken shortly before and after $\mathrm{T}_{0}$, were classified as "over-screened". 
Table I: Baseline characteristics of the Norwegian female population* in 1996 by pregnancy status, age, history of Pap smear and invitation to the cervical cancer screening programme

\begin{tabular}{|c|c|c|c|}
\hline & \multicolumn{3}{|c|}{ Pregnancy status } \\
\hline & Reference cohort 2060118 (\%) & Pregnant cohort 24297 (\%) & Mixed cohort 91 347 (\%) \\
\hline \multicolumn{4}{|l|}{ Age-groups } \\
\hline$<14$ & $445928(21.7)$ & $18(0.07)$ & II $(0.01)$ \\
\hline $15-19$ & $125039(6.1)$ & $1688(7.0)$ & $4090(4.5)$ \\
\hline $20-24$ & $130147(6.3)$ & $6087(25.0)$ & $20103(22.1)$ \\
\hline $25-29$ & $127742(6.1)$ & $9112(37.5)$ & $34809(38.1)$ \\
\hline $30-34$ & $13|08|(6.4)$ & 5555 (22.9) & $23530(25.8)$ \\
\hline $35-39$ & $144959(7.0)$ & $1653(6.8)$ & $7756(8.5)$ \\
\hline $40-44$ & $146978(7.1)$ & $178(0.7)$ & $1024(1.1)$ \\
\hline $45-49$ & $149296(7.2)$ & $6(0.02)$ & $24(0.03)$ \\
\hline $50-69$ & $394224(19.1)$ & - & - \\
\hline $70+$ & $267724(13.0)$ & - & - \\
\hline \multicolumn{4}{|l|}{$\begin{array}{r}\text { Time since last Pap smear } \\
\text { before } T_{0}\end{array}$} \\
\hline $0-12$ months & $44 \mid 735(2 \mid .4)$ & $9342(38.4)$ & $36318(39.8)$ \\
\hline 13-24 months & $278490(13.5)$ & $5934(24.4)$ & $23304(25.5)$ \\
\hline $25-36$ months & $181158(8.8)$ & $3662(15.1)$ & $13113(14.4)$ \\
\hline$>36$ months & I 158735 (56.2) & $5359(22.1)$ & $18612(20.4)$ \\
\hline \multicolumn{4}{|l|}{ Time since invitation } \\
\hline No invitation & I 567788 (76.1) & $18374(75.6)$ & $75393(82.5)$ \\
\hline $24-2$ months prior to $T_{0}$ & 229417 (II.I) & $2596(10.7)$ & $989(1.1)$ \\
\hline I months prior- 3 months after $T_{0}$ & 132981 (6.5) & $2256(9.3)$ & $3524(3.9)$ \\
\hline$>3$ months after $\mathrm{T}_{0}$ & $129932(6.3)$ & I07| (4.4) & II $44 \mid(\mid 2.5)$ \\
\hline
\end{tabular}

* 39707 were excluded because they were either born before 1900, diagnosed with invasive cervical cancer and/or underwent hysterectomy before 1996, died in 1997 or had inadequate data for estimating duration of the pregnancy

\section{Attendance to the screening following invitation letter}

When invitation was mailed close to $\mathrm{T}_{0}$, defined as 4 months, from one month prior to $\mathrm{T}_{0}$ to three months after $\mathrm{T}_{0}, 74.6 \%$ of $C_{\text {preg }}$ had a Pap smear in during one year of follow-up, compared to $37 \%$ of the $C_{r e f}$.

Pregnant women were almost 5 times more likely to have a Pap smear within one year of $\mathrm{T}_{0}$ compared to the nonpregnant women, crude OR $=4.7$ (95\% CI 4.6 to 4.8 ). After adjusting for age, time since last Pap smear and time since invitation, this estimate was somewhat lower, adjusted OR $=4.3$ (95\% CI 4.2 to 4.4 ) (Table 3). Women who had the last Pap smear more than 3 years since $\mathrm{T}_{0}$ had a smaller probability of a new Pap smear during the next one year compared to women who had a last smear taken within one year of $\mathrm{T}_{0}$, irrespectively of the pregnancy status, adjusted OR $=0.76$ (95\% CI 0.75 to 0.77$)$. When this estimate was limited to $C_{\text {preg, }}$ the OR was 2.6 (95\% CI 2.4 to 2.8), compared to OR of 0.73 (95\% CI 0.72 to 0.74 ) for the $C_{r e f}$ only. Compared to the non-pregnant women, pregnant women were 2.1 times more likely (95\% CI 1.9 to 2.4) to have a Pap smear following the invitation letter if the latter was mailed close to the beginning of $\mathrm{T}_{0}$, compared to the non-pregnant women.

\section{Discussion}

We found that smear taking activity during pregnancy in Norway was high, with $69 \%$ of pregnant women having had a Pap smear during one year of follow-up. Most of the Pap smears from pregnant women were taken during the antepartum period, within 4 months from the start of the pregnancy, and therefore they will be further referred as antepartum Pap smears. Norwegian guidelines state that $1^{\text {st }}$ trimester antepartum Pap is recommended given no normal smear was taken during the period of 2,5 years prior to the visit [16]. This recommendation is given regardless of age because the average $1^{\text {st }}$ full-time pregnant Norwegian woman is 29 years old and should already been participating at the screening. However, 58\% of pregnant women with a smear taken shortly before had also an antepartum Pap, reflecting the real-life situation, indicating poor adherence to the guidelines.

\section{Effect of an antepartum Pap smear to the coverage}

Compared to non-pregnant women, pregnant women were 4.3 times more likely to be screened by Pap smear during one year period, irrespectively of their age or screening history. As much as $76 \%$ of the pregnant women without a smear in three years prior to start of 
Table 2: Proportion of women with Pap-smear during one year follow-up by age, history of Pap smear and invitation to the cervical cancer screening programme

\begin{tabular}{|c|c|c|}
\hline & \multicolumn{2}{|c|}{ Women with Pap smear(s) in follow-up of 12 months } \\
\hline & Reference cohort $\mathrm{N}(\%)$ & Pregnant cohort N (\%) \\
\hline \multicolumn{3}{|l|}{ Age-groups } \\
\hline$<14$ & $1449(0.3)$ & 14 (77.8) \\
\hline $15-19$ & $24181(19.3)$ & $1115(66.1)$ \\
\hline $20-24$ & $44720(34.4)$ & $4261(70.0)$ \\
\hline $25-29$ & $45268(36.3)$ & $6349(70.0)$ \\
\hline $30-34$ & $44844(34.2)$ & $3725(67.1)$ \\
\hline $35-39$ & $47182(32.6)$ & $1097(66.4)$ \\
\hline $40-44$ & $48445(33.0)$ & $120(67.4)$ \\
\hline $45-49$ & $49775(33.3)$ & $3(50.0)$ \\
\hline $50-69$ & $95905(24.3)$ & - \\
\hline $70+$ & $14056(5.2)$ & - \\
\hline \multicolumn{3}{|l|}{ Time since last Pap-smear* before $\mathbf{T}_{0}$} \\
\hline $0-12$ months & $83023(32.3)$ & $5397(57.8)$ \\
\hline I3-24 months & $59021(36.9)$ & 4289 (72.3) \\
\hline $25-36$ months & $47100(46.0)$ & 2909 (79.5) \\
\hline$>36$ months & $65496(23.1)$ & $4072(76.2)$ \\
\hline \multicolumn{3}{|l|}{ Time since invitation* } \\
\hline No invitation & I85 99| (33.2) & $12732(69.4)$ \\
\hline $24-2$ months prior to $T_{0}$ & $26664(25.0)$ & $1737(67.0)$ \\
\hline I months prior- 3 months after $\mathrm{T}_{0}$ & $26455(37.4)$ & $1683(74.6)$ \\
\hline$>3$ months after $\mathrm{T}_{0}$ & $15530(23.7)$ & $515(48.1)$ \\
\hline
\end{tabular}

* age-groups 15-44 only

pregnancy had a smear in follow-up compared to $23 \%$ of the non-pregnant women. This large difference can partially be explained by the fact that more women in age of 15-24 years were included into the Reference cohort and therefore, should not have been screened at all. The age issues were taken into account by estimating the risk of a smear (adjusted for pregnancy status, age, or invitation) for women without the smear in three years period and for women who had smear shortly prior to the start of the study. It was somewhat surprising to observe that women without a smear within the last three years were less likely to have a smear compared to women who were screened lately, $\mathrm{OR}=0.76$. This figure can be explained by the observation that women with frequent smear taking activity were more likely to continue such a pattern, whereas women who had a smear taken rarely or never, were less likely to have a smear in the near future. One can postulate that one of the most important obligations of an organized CC screening programme is to minimise the proportion of women without a smear: and as a consequence, this risk estimate should eventually increase. As an example, pregnant women who had a last Pap smear more than three years prior to the start of the study, were 2.6 times more likely to have a smear in one year compared to women with a smear shortly before start of the study. The comparative figure for the non-pregnant women was 0.73 . Together with the fact that pregnant women showed a higher probability of a favourable response to smear taking by invitation letter than nonpregnant women OR $=2.12(95 \%$ CI 1.89 to 2.38$)$ it implies that Pap smear in pregnancy increases the coverage of the programme.

Elucidating as to why almost two-thirds of non-pregnant women aged 15-44 years with an invitation letter did not have Pap smear, and why there was a three times higher attendance rate among pregnant women compared to non-pregnant women is important. Possibly an explanation lies in the relatively high work load of the women: they are usually either studying, have just joined the work force, have established a family, already have small children to tend to, or carry out a combination of these duties. The need for a regular check up for precursors of cervical cancer could be given less priority in such demanding/ real-life settings. This explanation is in line with a Swedish study, where Eaker concluded that non-attendance to cervical cancer screening is rather practically rooted.[18] A study from the U.S. identified no effect of either patient or physician reminders on Pap smear completion, while patients with a chronic illness had a three times higher 
$\%$ of women with Pap smear

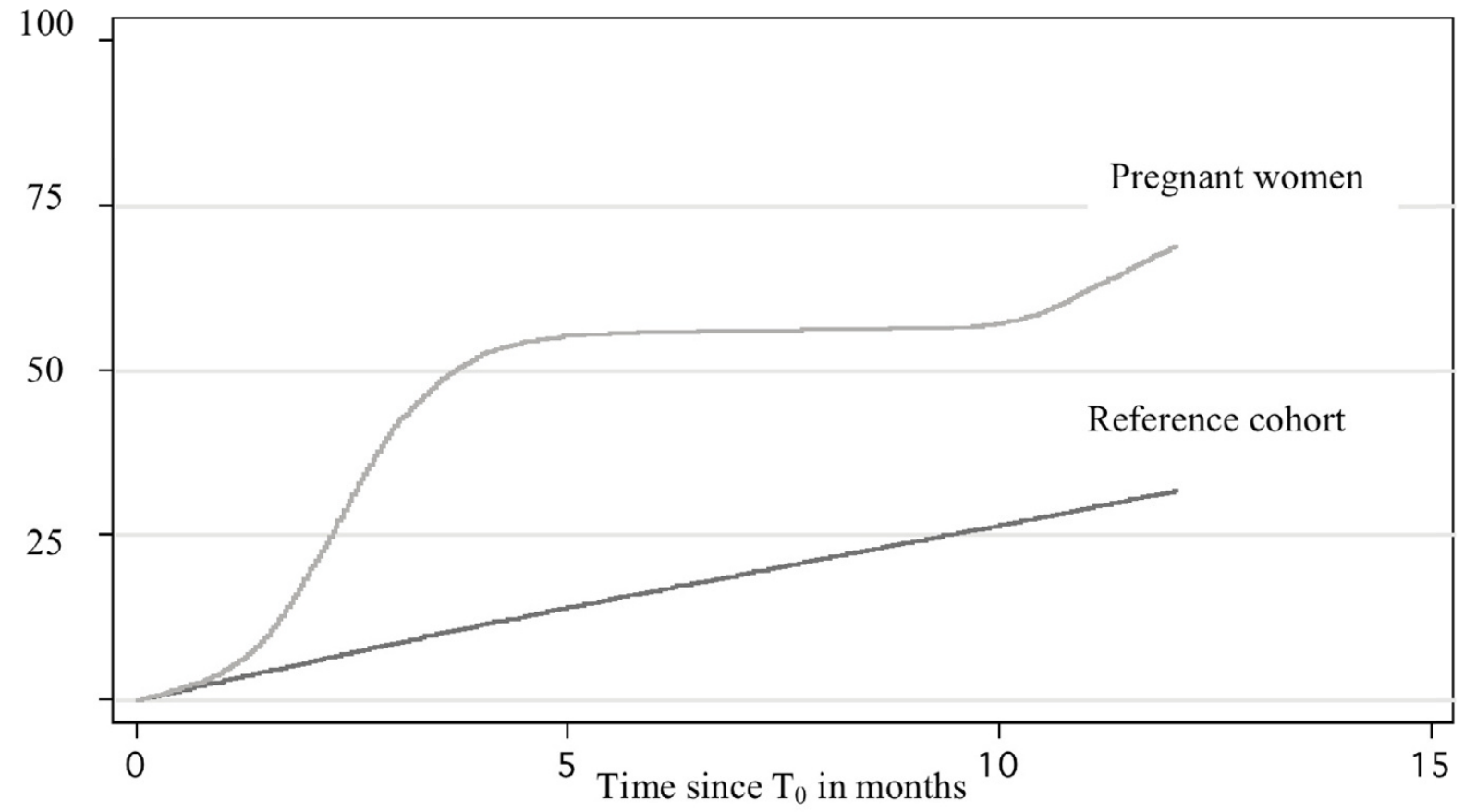

Figure I

Cumulative probability for Pap smear since $T_{0}$ for women in age of I5-44 years, for the Reference and Pregnant women cohorts by Kaplan Meieranalyses. $Y$-axes refer to the proportion of women with Pap smear and $X$-axes refer to time in months from the start of follow-up. The increase of proportion of women with Pap smear during follow-up time is depicted separately for Pregnant women cohort (light grey line) and for the Reference cohort (black line).

probability of Pap smear completion,[19] indicating that access to health care is a lesser issue for those with chronic diseases.

\section{Pap smear screening among women before screening age}

Only $32 \%$ of the pregnant women were $<25$ years old and expected to be not screened due to young age. Women aged 15-19 had Pap smears in follow-up period more seldom than women aged 25-29 years, OR $=0.53$. However, the probability of a smear was $66.1 \%$ for pregnant women compared to $19.3 \%$ for non-pregnant women indicating that antepartum Pap contributed to increased screening among young women. In absolute terms, 1129 pregnant women aged 15 to 19 years had a smear during the one-year period. If all pregnant women in this young age group would have had a smear, the consequent number would have been 1706 compared to 25630 nonpregnant young women. It is clear that other factors than pregnancy seems also relevant in explaining the Pap smear-taking activity among young women. It should be remembered that a sexually transmitted virus, human papilloma virus, is responsible for developing pre-invasive cervical lesions and CC [20,21]. Pregnant women irrespective of age therefore represent a population with a past or current exposure to sexually transmitted infections. However, many mild dysplastic cervical lesions are subjected to regress, as we have shown in our previous study on young women [22], suggesting that mass-screening in young ages is unwarranted.

\section{Does Antepartum Pap smear contribute to "over- screening"?}

Altogether $32 \%$ of non-pregnant and 58\% of pregnant women were classified as "overscreened", as defined by repeated Pap-smears in short period of time, emphasizing the fact that pregnant women taking an antepartum Pap cannot be solely the reason for the frequent screening observed. Further, the overall proportion of pregnant women in the population is small: expressed in the absolute numbers as much as 83023 of non-pregnant compared to 5397 pregnant women underlines that the antepartum Pap does not substantially constitute to the overall number of extra smears taken.

In the current study in assessing the effect of pregnancy on coverage only we did not consider the possibility that Pap 
Table 3: Probability for Pap smear within one year since $\mathrm{T}_{0}$. Crude and adjusted odds ratios (OR) and $95 \%$ confidence intervals (Cl) were estimated by logistic regression

\begin{tabular}{|c|c|c|c|c|}
\hline & \multicolumn{4}{|c|}{ Probability for Pap smear within 12 month since $T_{0}$} \\
\hline & Crude OR & $95 \% \mathrm{Cl}$ & Adjusted OR & $95 \% \mathrm{Cl}$ \\
\hline Reference cohort & 1 & ref. & 1 & ref. \\
\hline Pregnant ccohort & 4.72 & $4.59-4.85$ & 4.28 & $4.16-4.40$ \\
\hline \multicolumn{5}{|l|}{ Age-groups } \\
\hline $15-19$ & & & 0.53 & $0.52-0.54$ \\
\hline $20-24$ & & & 0.95 & $0.94-0.97$ \\
\hline $25-29$ & & & 1 & ref. \\
\hline $30-34$ & & & 0.91 & $0.89-0.92$ \\
\hline $35-39$ & & & 0.85 & $0.84-0.87$ \\
\hline $40-44$ & & & 0.88 & $0.87-0.90$ \\
\hline \multicolumn{5}{|l|}{$\begin{array}{r}\text { Time since last Pap- } \\
\text { smear* }\end{array}$} \\
\hline $0-12$ months prior to $T_{0}$ & & & 1 & ref. \\
\hline 13-24 months prior to $T_{0}$ & & & 1.22 & $1.20-1.24$ \\
\hline $25-36$ months prior to $T_{0}$ & & & 1.77 & $1.75-1.80$ \\
\hline$>36$ months prior to $T_{0}$ & & & 0.76 & $0.75-0.77$ \\
\hline \multicolumn{5}{|l|}{ Time since invitation* } \\
\hline No invitation & & & I & ref. \\
\hline $24-2$ months prior to $T_{0}$ & & & 0.91 & $0.89-0.92$ \\
\hline $\begin{array}{l}\text { I months prior-3 months } \\
\text { after } T_{0}\end{array}$ & & & 2.12 & $1.89-2.38$ \\
\hline$>3$ months after $T_{0}$ & & & 1.00 & $0.92-1.09$ \\
\hline
\end{tabular}

smears taken shortly before the start of the follow-up were abnormal, and as defined, that they should be followed up soon after with a Pap smear. Nor did we consider that the onset of clinical symptom(s) leading to a new Pap smear. These are relevant concerns that we cannot appropriately address in this study design. However, there are no strong reasons to suspect large difference in the two cohorts in these respects. Taking into consideration that the proportion of abnormal Pap smear is low in the programme: approx. $86 \%$ of all the smears are normal, and any existing differences in the distribution of abnormal smears in the pregnant and non-pregnant women are likely to be only weakly affect the estimates of coverage.

It is natural combine the antepartum visits with the distribution of the health education among women and several authors demanding the routine antepartum smear $[23,24]$ in order to improve diagnosis of the CIN. However, the decision on recommending Pap smears for all pregnant women should be based on information on the accuracy of the antepartum Pap to diagnose underlying pre-invasive lesion, the impact on coverage and on the mean ages of pregnancy in given country.

\section{Conclusion}

Several studies have been performed to assess the value of a Pap smear collected during the antepartum and/or post- partum period. Conclusions regarding the necessity of routine Pap smear(s) during pregnancy are often missing or, sometimes contradictory, reflecting that information on availability or history about cervical cancer screening is often unavailable. This registry linkage study has been conducted to estimate the effect of Pap smear during pregnancy on the coverage, and our study suggests that the provision of Pap smears to all pregnant women in Norway will increase the coverage of the programme. The contribution of such an action on over-screening and screening among young women is likely to be modest in the country where in the average, women become pregnant after the recommended age of screening.

\section{Competing interests}

The author(s) declare that they have no competing interests.

\section{Authors' contributions}

$\mathrm{MN}, \mathrm{AKD}, \mathrm{S} \varnothing \mathrm{T}$ and JFN participated actively in the design of the study and helped to draft the manuscript. JFN carried out the statistical analyses; $\mathrm{MN}$ and $\mathrm{AKD}$ participated in data base compiling; $\mathrm{MN}$ had main responsibility to perform this study. All authors read and approved the final manuscript. 


\section{Acknowledgements}

Authors would like to acknowledge Mr. Tormod Eriksen for he's help in providing data on Norwegian female population for this study and Dr. Freddy I Bray for reviewing early draft of this manuscript.

\section{References}

I. Parkin DM, Bray F, Ferlay J, Pisani P: Global cancer statistics, 2002. CA Cancer J Clin 2005, 55(2):74- 108.

2. Gustafsson L, Ponten J, Zack M, Adami HO: International incidence rates of invasive cervical cancer after introduction of cytological screening. Cancer Causes Control 1997, 8(5):755-763.

3. Anttila A, Nieminen P: Cervical cancer screening programme in Finland. Eur J Cancer 2000, 36(I 7):2209-2214.

4. Baker D, Middleton E: Cervical screening and health inequality in England in the I990s. J Epidemiol Community Health 2003, 57(6): $417-423$.

5. Hakama M: Potential contribution of screening to cancer mor tality reduction. Cancer Detect Prev 1993, I 7(4-5):5 I 3-520.

6. Segnan N, Ronco G, Ciatto S: Cervical cancer screening in Italy. Eur J Cancer 2000, 36( I 7):2235-2239.

7. Sigurdsson K: The Icelandic and Nordic cervical screening programs: trends in incidence and mortality rates through 1995 Acta Obstet Gynecol Scand I999, 78(6):478-485.

8. van Ballegooijen M, van den Akker-van Marle E, Patnick J, Lynge E, Arbyn M, Anttila A, Ronco G, Dik J, Habbema F: Overview of important cervical cancer screening process values in European Union (EU) countries, and tentative predictions of the corresponding effectiveness and cost-effectiveness. Eur J Cancer 2000, 36(17):2177-2188.

9. Aareleid T, Pukkala E, Thomson H, Hakama M: Cervical cancer incidence and mortality trends in Finland and Estonia: a screened vs. an unscreened population. Eur J Cancer 1993, 29A(5):745-749.

10. Hristova L, Hakama M: Effect of screening for cancer in the Nordic countries on deaths, cost and quality of life up to the year 2017. Acta Oncol 1997, 36 Suppl 9: I-60.

II. Janerich DT, Hadjimichael O, Schwartz PE, Lowell DM, Meigs JW, Merino MJ, Flannery JT, Polednak AP: The screening histories of women with invasive cervical cancer, Connecticut. Am J Public Health 1995, 85(6):79|-794.

12. Nygard JF, Skare GB, Thoresen SO: The cervical cancer screening programme in Norway, 1992-2000: changes in Pap smear coverage and incidence of cervical cancer. J Med Screen 2002, 9(2):86-9l.

13. Nygard JF, Nygard M, Skare GB, Thoresen SO: Screening histories of women with CIN 2/3 compared with women diagnosed with invasive cervical cancer: a retrospective analysis of the Norwegian Coordinated Cervical Cancer Screening Program. Cancer Causes Control 2005, I 6(4):463-474.

14. Eaker S, Adami HO, Sparen P: Attitudes to screening for cervical cancer: a population-based study in Sweden. Cancer Causes Control 2001, I 2(6):519-528.

15. Statistisk årbok. Volume / 19. Oslo, Official Statistics of Norway; 2000.

16. Hofvind S, Nygård J, Olsen Olaug A, Sauer T, Skare Baadstrand G, Skjeldestad F, Thoresen S: Masseundersøkelsen mot livmorhalskreft i Norge. Evaluering av programmet 1992-98. Oslo Kreftregisteret, Institute of population-based cancer research; 200I.

17. Clayton D, Hills M: Statistical Models in Epidemiology. New York , Oxford University Press Inc; 1996:367.

18. Eaker S, Adami HO, Sparen P: Reasons women do not attend screening for cervical cancer: a population-based study in Sweden. Prev Med 200I, 32(6):482-49I.

19. Burack RC, Gimotty PA, George J, McBride S, Moncrease A, Simon $M S$, Dews $P$, Coombs J: How reminders given to patients and physicians affected pap smear use in a health maintenance organization: results of a randomized controlled trial. Cancer I998, 82( ( 2):239|-2400.

20. IARC: IARC Handbooks of Cancer Prevention. In Cervix Cancer Screening Volume 10. Lyon, IARC Press; 2005:217.

21. IARC: Human papillomaviruses. In IARC Monographs on the evaluation of carcinogenic risks to humans Volume 64. Lyon , International Agency for Research in Cancer; 1995:378.

22. Nygard JF, Nygard M, Skare GB, Thoresen SO: Pap smear screening in women under 30 in the Norwegian Coordinated Cer- vical Cancer Screening Program, with a comparison of immediate biopsy vs Pap smear triage of moderate dysplasia. Acta Cytol 2006, 50(3):295-302.

23. Allen DG, Planner RS, Tang PT, Scurry JP, Weerasiri T: Invasive cervical cancer in pregnancy. Aust N Z J Obstet Gynaecol 1995, 35(4):408-4I2.

24. Guerra B, De Simone P, Gabrielli S, Falco P, Montanari G, Bovicelli L: Combined cytology and colposcopy to screen for cervical cancer in pregnancy. J Reprod Med 1998, 43(8):647-653.

\section{Pre-publication history}

The pre-publication history for this paper can be accessed here:

http://www.biomedcentral.com/1472-6963/7/10/prepub
Publish with Biomed Central and every scientist can read your work free of charge

"BioMed Central will be the most significant development for disseminating the results of biomedical research in our lifetime. "

Sir Paul Nurse, Cancer Research UK

Your research papers will be:

- available free of charge to the entire biomedical community

- peer reviewed and published immediately upon acceptance

- cited in PubMed and archived on PubMed Central

- yours - you keep the copyright
BioMedcentral 